\title{
Conscious Use of Self: Tuning the Instrument of Social Work Practice with Cultural Competence
}

\author{
Margo J. Heydt and Nancy E. Sherman
}

The authors provide definitions and describe teaching methods and strategies related to a renewed understanding and development of the concept of "conscious use of self," a term defining the social worker as the "instrument" purposely used to promote change with client systems. The article clarifies how conscious use of self affects the development of an effective helping relationship, the medium through which change occurs in social work practice. Emphasis is placed on integrating cultural competence within students' understanding of conscious use of self as well as applying the concept at both micro- and macrolevels of intervention.

Key words: cultural competence, helping relationships, use of self

\section{The Instrument}

Rock bands depend on their drummers to set the beat. However, musicians are not the only professionals who play an instrument. Most professions, both helping and otherwise, can readily be identified by a representative instrument or primary practice tool used in the profession: carpenters use a hammer; artists use paint; writers use typewriters and computers; and chemists use beakers. More specifically in the helping professions, fire fighters use hoses and ladders; dentists use drills; doctors use stethoscopes; nurses use syringes to give injections; and psychologists administer tests to get information. Asking students to name the instrument used by social workers usually stumps them. The realization that social workers themselves are the instruments of the profession usually has a sobering effect on beginning social work students.

\footnotetext{
Margo J. Heydt, Ed.D., LISW, ACSW, is Assistant Professor in the Department of Social Work at Xavier University in Cincinnati, Ohio. Nancy E. Sherman, Ph.D., LCPC, NCC, is Associate Professor and Director of the Counseling, Research, and Training Clinic at Bradley University in Peoria, Illinois.
} 


\section{Proper Tuning of the Instrument}

Identifying the social worker as the instrument of the profession who acts as the agent of change in an effective helping relationship with a client system paves the way for introducing concepts related to self-awareness of the social worker. Conscious use of self is the term used by social workers to describe the skill of purposefully and intentionally using "his or her motivation and capacity to communicate and interact with others in ways that facilitate change" (Sheafor \& Horejsi, 2003, p. 69). Usually, this concept of conscious use of self is a new concept for students. When placed in the context of a helping relationship, in which a social worker is guiding a planned change process, students are better able to grasp the meaning and significance of the concept.

Although new to students, conscious use of self is not a new concept in social work. For a concept that most consider basic to the field of social work, however, a search of the current literature reveals less than expected. As documented by various authors (Lee, 1983; Specht \& Courtney, 1994; Leiby, 1997; Jacobson, 2001), the shift in social work from its early emphasis on social reform to its current emphasis on clinical practice also appears to have shifted the focus from conscious use of self at multiple levels of intervention to self-awareness within a one-on-one helping relationship. In discussing this shift, Jacobson (2001) states:

Clinical practitioners are taught that self-knowledge is vital to detecting transference, counter transference, and other dynamics in the therapeutic relationship. But, although key to therapeutic practice, such efforts to "know oneself" have not been emphasized as a foundation for nonclinical social work activities, such as income maintenance work, employment training, child welfare, or nutritional support. (p. 55)

The importance of the concept of conscious use of self to the field of social work warrants an emphasis on self-awareness as a foundation to understanding the role of conscious use of self in the development of effective helping relationships at micro- and macrolevels of intervention. In other words, tuning one's self as the instrument of change is not just about playing better duets.

This article offers teaching strategies to develop a foundation level of selfawareness in undergraduate social work students. Examples show how conscious use of self and cultural competence are necessary to develop effective helping relationships at both micro- and macrolevels. Incorporating cultural competence in the development of self-awareness and conscious use of self moves toward compliance with the NASW (2001) Standards for Cultural Competence in Social Work Practice.

\section{Self-awareness and Conscious Use of Self are Not Synonyms}

Various authors describe the planned change process in social work (Cournoyer, 2000; Ivey \& Ivey, 1999; Sheafor \& Horejsi, 2003; Shulman, 
1999). Certain social work skills typically are used throughout this process. These skills, however, are all purposefully or intentionally used within the context of the helping relationship, whether practice is at the micro-, mezzo-, or macrolevel. Shulman $(1999$, p. 22) depicts this concept in a description of his interactional theory of social work practice in the graphic below:

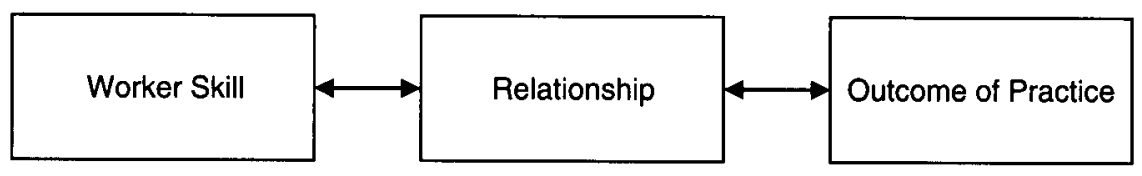

This theory suggests that the skill of the social worker is integral in creating a positive working relationship, which is then the medium through which the social worker consciously influences the outcomes of practice. Neuman and Friedman (1997) emphasize the importance of self-awareness and conscious use of self in the building of the relationship by identifying two key ingredients: self-awareness through mastery of one's feelings and motivations as well as understanding how he or she is perceived by clients.

Encouraging students to compare conscious use of self with its opposite, unconscious use of self, further clarifies the concept. Operating in a "seat of the pants" manner or helping in a certain way just because it feels right to do so is not acting in the manner of a professional social worker. Most students state that they enter social work because they want to help others. Even those with the highest motivation and best of intentions may inadvertently express themselves in unhelpful or harmful ways without adequate self-awareness. As Cournoyer (2000) describes:

Because social work practice involves the conscious and deliberate use of oneself, you become the medium through which knowledge, attitudes, and skill are conveyed. ... You might have the most noble and idealistic of motives, intending only to serve others. Nonetheless, if you lack self-awareness, you may unwittingly enact emotional or behavioral patterns that harm the very people you hope to help. (p. 35)

The personal values, attitudes, prejudices, and beliefs of social workers affect how helpful they can be to their clients. Social workers reveal these values and beliefs to clients in professional relationships directly and indirectly. The more consciously aware workers are of how their own beliefs, perceptions, and behaviors impact their professional relationship, the more consciously they can choose how to influence the helping relationships in which they are involved. Display of unexamined attitudes, either consciously or unconsciously, may be perceived as barriers by micro-, mezzo-, and macrolevel client systems. Therefore, developing self-awareness in order to make the most effective conscious use of self must also include working toward the development of cultural competence.

The National Association of Social Workers' (NASW) Code of Ethics (1996) 
refers to culturally-competent practice as the ethical responsibility of social workers at both the micro- and macrolevels of intervention in Sections 1.05 and 6.04. In 2001, the NASW Board of Directors adopted 10 standards for cultural competence in social work practice. The standards are based on the Code of Ethics as well as the policy statement, Cultural Competence in the Social Work Profession, published in Social Work Speaks: NASW Policy Statements (2000). As defined in the NASW Standards for Cultural Competence in Social Work Practice (2001), "Cultural competence is a set of congruent behaviors, attitudes, and policies that come together in a system or agency or among professionals and enable the system, agency or professionals to work effectively in cross-cultural situations" (p. 11). Although acknowledging that this does not come naturally, the policy recommends that social workers must acquire cultural competence by turning cognitive learning into affective insight: “. . . workers need to move from cultural awareness to cultural sensitivity before achieving cultural competence ..." (p. 17). The second of the 10 standards directly addresses selfawareness stating: "Social workers shall seek to develop an understanding of their own personal, cultural values and beliefs as one way of appreciating the importance of multicultural identities in the lives of people" (p. 4). In the interpretation discussion of this standard, cultural competence is further defined as including: "knowing and acknowledging how fears, ignorance, and the 'isms' (racism, sexism, ethnocentrism, heterosexism, ageism, classism) have influenced their attitudes, beliefs, and feelings" (p. 17). The eighth of the 10 standards addresses professional education and identifies the need for "... educational and training programs that help advance cultural competence within the profession" (p. 5). Therefore, incorporating cultural competence within the development of self-awareness and conscious use of self in undergraduate students not only contributes to more effective helping relationships, but also helps move the profession further toward these stated goals.

Many of those personal values, attitudes, and beliefs that are revealed to clients through well-intended helping relationships may attest to the extent of ignorance or prejudices existing within students. When the existence and depth of such prejudices remain unexamined, they interfere with the establishment and maintenance of helping relationships with certain populations or under certain circumstances. Just as artists clean their paintbrushes and fire fighters inspect their equipment to keep their instruments in perfect working order, every social worker needs to examine his or her own attitudes, personal habits, and interactional patterns in order to enhance the conscious use of self and become the most effective instrument of change possible for as many of their clients as possible. When considering cultural competence in particular, Neuman and Freidman's (1997) description of conscious use of self as including both "an awareness and mastery of one's feelings, motivations, and skill levels" as well as "self-awareness and perception of how the client perceives him or her" (p. 22) bears repeating.

This need for awareness, of perceptions both internally and externally holds 
true at the macrolevel when requesting funding from an area $\mathrm{CEO}$, as well as at the mezzolevel when facilitating a group for child abuse survivors or addressing the needs of one homeless person at the microlevel. Because social workers apply their skills with many kinds of populations in many types of settings at micro-, mezzo-, and macrolevels of intervention, conscious use of self also needs to be developed on a multilevel basis that is appropriate for multiple populations and settings. Although the tendency is to focus on conscious use of self as self-awareness at the microlevel, the application is just as important at the mezzo- and macrolevels where multiple players are involved. Awareness of how the client system perceives the worker as a group therapy facilitator, agency director, or grassroots community organizer may be even more essential to the development of effective macrolevel helping relationships due to increased interclient interactions.

Examples that specifically state and demonstrate this in the literature are scarce. Lee (1983) illustrates the concept very well, however, in "The Social Worker in the Political Environment of a School System." Describing schools as "a political arena in which actors cognitively and experientially wrestle with political forces" (p. 302), Lee states:

The major tool of social work performance is the worker's conscious use of self in relation to significant others. ... The worker's intentional establishment and maintenance of supportive relationships with influential persons within and outside the school system are key determinants of whether he or she will remain in the system and will be able to assist in students' education. (p. 302)

Lee's (1983) article explores such macroissues as access to information and how to use it, maintaining credibility within the organization, connecting the goals of school social work with those of the overall school system, and being able to establish effective relationships with interdisciplinary school personnel. One of Lee's examples examines a macrounderstanding of the difference between winning the battle vs. winning the war. In the situation described, selfawareness may be sufficient for understanding one's role in the immediate conflict, or battle, and for determining that filing formal grievance charges might be a legitimate avenue for resolution. Lee, however, advocates for purposefully or intentionally choosing "to resolve conflicts informally as they arise" over engaging in formal grievance procedures whenever possible because:

It is a system's expectation that employees will not engage in behavior that embarrasses the system, and there is a price to be paid for drawing public attention to in-house struggles. (p. 305)

The act of consciously choosing to resolve conflicts informally demonstrates conscious use of self efforts toward winning the war rather than only the battle by taking into account the perceptions of others as well as awareness of one's own role in the conflict. 
In host settings such as a school, the social worker is no longer just one instrument playing a "duet" with one other instrument. At the family, institutional, or community level, the social worker becomes both player and conductor in the chamber orchestra. Unknowingly conducting off beat may ruin the music for involved "players" and "listeners" in the family, institution, or community alike. This kind of self-awareness required for cultural competence and effective conscious use of self by social workers at the macrolevel goes well beyond just being "in tune" with oneself. As in the world of professional musicians, not only do the strings of a guitar or violin need to be in tune with each other, but each guitar or violin also needs to be in tune with the rest of the band or orchestra.

\section{Teaching Strategies Developing Conscious Use of Self}

A concept as central to the practice of social work as conscious use of self should be taught at some level throughout the social work curriculum. Practice classes, however, usually become the laboratory where most students practice applying conscious use of self. At a minimum, Cournoyer (2000) recommends that social workers "develop substantial understanding of how their families and their ecological environments affected their development and influence their psychosocial functioning" (p. 13). A discussion of how most people carry some family roles with them contributes to the understanding that we all have thoughts, feelings, and behaviors that influence us without our conscious knowledge (Wegscheider, 1981).

Continuing that discussion with questions about what it is like to hear oneself talking on an audiotape or see a photograph or videotape of oneself that is barely recognizable helps personalize the idea that others may hear and see us differently than we perceive ourselves. Increased self-awareness, both internally, in how we perceive ourselves, and externally, in how others perceive us, can then be emphasized as being essential to improving any social worker's conscious use of self. Such self-awareness efforts, however, should identify both strengths and limitations.

Although bolstering strengths comes fairly easily to most, humans tend to struggle more when the focus is on factors that may obstruct or negatively impact a client relationship. Sheafor and Horejsi (2003) list eight of the more common factors that can interfere with the development of the helping relationship that should be part of a social worker's self-awareness examination. They include: 1) personal issues; 2) appearance, clothing, and grooming; 3 ) behaviors that devalue or degrade others; 4) distracting personal habits; 5) difficulties in verbal communication; 6) difficulties in cognitive functioning; 7) problems in written communication; and 8) poor work habits (pp. 578-580).

The first five of Sheafor and Horejsi's (2003) self-awareness factors are commonly addressed directly in a practice class, although one author has used some of the teaching strategies described in social institutions and seminar classes. The following section briefly explores each of these five factors and describes re- 
lated teaching strategies used by the authors in the classroom. Of the remaining three factors from their list, written communication and cognitive functioning difficulties should be addressed throughout the college curriculum as well as within all the social work major courses. Although poor work habits may surface through certain practice assignments and other coursework, these issues more commonly appear later during field placement, and are not the focus here.

\section{Personal Issues}

The first factor from Sheafor and Horejsi's (2003) list, personal problems and emotional issues, includes preoccupation with personal problems such as divorce or the illness of a family member; one's own mental illness, physical illness, or addiction; repeatedly avoiding certain clients or tasks such as placing clients with the most demanding problems at the end of the list to return calls or not completing client documentation in a timely manner; extreme defensiveness of one's own position without consideration of other perspectives; and imposing one's values and beliefs on clients. Although much of the overt behavior described here may not appear until a student is in a field placement, establishing the ongoing need for self-examination throughout one's career begins with self-awareness assignments as a student.

Family Self-Awareness One fairly common teaching strategy focused on personal issues consists of a self-awareness assignment that includes a genogram of students' own families, a mind map (an eco-map that also incorporates concepts and ideas), a life-history grid associated with the development of their interest in becoming a social worker, and a reflection and analysis paper about what they learned from completing those exercises. The reflection part used by one author also asks students to explore ideal vs. real conceptions of family, to explain how positive and negative things they learned from their families are likely to affect their work, and to identify enhancing and depleting relationships between people/ideas/activities in their current situations. Students end the assignment by analyzing what they learned about their own strengths and possible challenges they may face as they prepare to become social workers. Guidelines about confidentiality are discussed in class and provided in writing. For traditional-age undergraduate students, very few have completed exercises such as this before on a personal level. Even fewer have directly applied such insight to the concept of conscious use of self and their professional growth.

\section{Appearance and First Impressions}

The second category from Sheafor and Horejsi's (2003) list includes appearance, clothing, and grooming. Emphasizing the importance of clients' first impressions of their social worker stimulates discussion about appearing in any 
way that distracts the client or worker from establishing a helping relationship. The lack of personal hygiene, apparent medical conditions that may cause worry or anxiety, or trendy clothing and/or hairstyles are explored as examples. Most helping professions are not only identified by an instrument, but also by a uniform of some kind. Spirited discussions develop regarding expression of personal preference and individuality as it affects conscious use of self and development of the helping relationship. The class is asked to consider what they might do regarding appearance if their job required them to spend half of a day working at a teen drop-in center followed by meeting with the Chamber of Commerce to solicit community support for that center. Choosing to wear a uniform of jeans, multiple earrings, and running shoes that might work very well when establishing microlevel relationships with teens at a drop-in center could easily be viewed as a lack of respect or credibility by the Chamber of Commerce just as wearing a three-piece suit and tie for the macrolevel Chamber of Commerce might interfere with relating to teens.

First Impressions Visualization One strategy to demonstrate the power of first impressions uses a visualization exercise in which students share their own first impressions from the following verbalized first-day-of-class scenarios depicting a variety of professors as they walk into the classroom: 1) a male in a T-shirt and jeans with one earring, sandals, and a ponytail; 2) a female in a navy blue suit with matching pumps, gold button earrings, and short trim hair; 3 ) a female in a T-shirt and jeans with seven earrings, sandals, and a ponytail; 4) a male in a sport coat, khaki pants, and a collared shirt with no tie; 5) a female in a long flowing skirt with a loose sweater, long straight hair, dangly earrings, and beads; and 6) a male in a gray-pinstripe three-piece suit with a red tie and dress shoes. Students readily share first impressions from both the visualization and real-life experiences as well as how that first impression of a professor affects them throughout the rest of the semester. Students are then asked to visualize some of the same scenarios, but change the race or have the professor come into class in a wheelchair, which leads to further discussion. Most agree that this helps them understand that clients are likely to judge them in similar ways in their first encounters as social workers.

\section{Cultural Competence}

Sheafor and Horejsi's (2003) third factor refers to development toward cultural competence by being aware of and avoiding behaviors that devalue or degrade others including disrespectful speech, sexist or ethnic jokes, promulgating stereotypes, or prejudicial comments regarding clients or client groups. Cultural competence requires more than engaging in non-offensive speech or increasing appreciation for diversity through activities such as exposure to differing cultural holiday celebrations. Using examples of how differences play out in every- 
day life illustrates reality in a way that helps students realize that prejudice and discrimination are multilevel and are experienced on a regular basis by many.

Greeting Cards Identity One teaching strategy for cultural competence revolves around a discussion about greeting cards. In a classroom of mostly white students, asking if they would buy the birthday card with the very best writing and illustrations on it for their mother or significant other if it had a picture of a person from a different race on it begins a discussion with interesting results. Asking who has noticed that certain greeting card displays showed mostly one race usually brings grins of recognition from students of color. Asking students if they think a card could be found for a gay biracial couple celebrating the tenyear anniversary of their civil union ceremony stimulates the next level of discussion. Discussion of what it would feel like to not be able to find a greeting card that reflects your identity or lifestyle is usually illuminating to those who take such everyday events for granted.

Early Recollections of Identity Self-awareness exercises that draw on students' earliest memories or recollections of realizing their own identity in terms of gender, race, ethnicity, class, religion, or any other identifying factor also provide a foundation for this kind of understanding and insight. This could include identifying what common positive and negative attributes family, neighbors, and classmates ascribed to one's own identity and the identity of those from another gender/race/class from grade school and high school. In one exercise, students are asked to describe their earliest memories of at least three "persons" from the following list: someone who was obviously of a lower socioeconomic class or was perhaps homeless, who had a skin color different from one's own, who was very old, who was very young, who was acting strangely or was obviously mentally ill, who was of a different sexual orientation, who had an unusual and severe physical disability or physical deformity, who was mentally challenged or had a severe developmental disability, who was of a different religion, or who was obviously of a higher socioeconomic class. Class discussion of similarities and differences among and between students' experiences contributes to a new level of understanding about the origins of such beliefs, attitudes, and behaviors. This then leads to examination of how those cognitive and affective aspects can consciously or unconsciously become displayed behaviors that may need modification.

Two activities that further illustrate strategies for cultural competence development as it relates to self-awareness and conscious use of self and promote discussion at micro- and macrolevels include reading an article written by an African American male sexual abuse survivor who struggles to recover through group therapy with white group members, and student performance of a short skit in the classroom in which an African American man explains his feelings about experiencing discrimination and prejudice in his lifetime. 
Sexual Abuse Survivor: An African American Male In an article describing racism and recovery from sexual abuse, attorney M.E. Hart (1992) provides an excellent example of the intersection of these issues on micro-, mezzo-, and macrolevels:

I am an African-American male whose abuse, perpetrated by multiple abusers, began at age four and lasted for 15 years. The camaraderie and understanding of the groups I worked with helped me rebuild my selfesteem and regain control of my life. During my recovery, however, I noticed a troubling trend. I was, in most cases, the only African-American in the groups I attended. Other African-Americans would not stay in the group for more than three or four meetings ... I tried to be supportive and encourage them to continue in the program. In most cases, I was not successful. (p. 1)

Hart identifies how both internal and external racial prejudices played a part in his life and especially in his recovery from the effects of the sexual abuse in his childhood. He advocates honest communication as the primary bridge to get past racial barriers. Not only are most students amazed at the concerns he reveals regarding his race, but all students seem to resonate to his direct approach recognizing his recommendations as important for society in general at the macro level as well as for individual survivors of abuse in group therapy.

Process Recording Reenactment Another example of the intersection of microand macroissues is provided by a student process recording exercise from a practice text that can also be used as a skit that students can easily perform in class (Strom-Gottfried, 1998). The exercise documents a session conducted by a young white female MSW student with a 47-year-old African American male who is in the hospital recovering from an amputation. Three actors are required: the student social worker, the client, and a narrator to read the process recordings. Describing his anger about an incident of discrimination that had happened to him in the hospital cafeteria, the client explains how he can tell the difference between that and when someone is just having a bad day based on incidents throughout his life. Students in class easily relate to the student in the skit who feels very uncomfortable with the client's repeating of racial slurs and who has no idea how to respond to what happened. The enactment provides a forum for class discussion about racism, about how to respond to any "ism" as a social worker, and about possible avenues when one has no idea how to respond.

Processing examples such as these spoken by those who have experienced prejudice and discrimination contributes directly to self-awareness related to cultural competence on cognitive and affective levels. Moving the discussion beyond just "tuning one's own instrument" to conscious use of self can move understanding from micro- to mezzo- and macrolevels. Related questions to consider include: a) techniques group leaders can use at the mezzolevel to increase the comfort levels of members from oppressed groups; b) how might the social 
work student's supervisor at the hospital or college field coordinator advise the student regarding such incidents of racism or any other "ism"; and c) efforts a social worker or student might engage in at his or her work setting to reduce everyday prejudice and discrimination.

\section{Budgeting a Poverty-Level Income}

When teaching about cultural competence, the "isms" related to gender, race, and ethnicity tend to be more commonly addressed. Teaching strategies that establish a micro- as well as macrounderstanding of poverty and class issues that reaches students at both the cognitive and affective levels can be more challenging to find. One author has used a variation of the "Budgeting a Poverty Level Income" exercise from Lieberman's (1998) The Social Workout Book: Strength Building Exercises for the Pre-Professional. As stated in the text, the goals of the workout are to explore assumptions and enable critical thinking about the meaning of poverty, the reality of the poverty threshold, minimum wage debates, and welfare reform in this country.

Lieberman (1998) provides an introductory reading that sets the stage regarding the macropoverty policy issues as well as describing an imaginary family of four including two recently laid-off parents and two children, ages two and six. The family has reluctantly moved in search of new jobs and has been able to bring along a few belongings. This is followed by a lengthy blank family annual line-item budget organized within the following thirteen categories: housing, utilities, maintenance, transportation, education, insurance, food, wardrobe, personal care/sundries, medical care, dependent care, discretionary expenses (entertainment, birthdays, vacation, holidays, postage), and miscellaneous. The class is divided into small groups and assigned two, three, or four of the budget subcategories, depending on the size of the class. Each group must research the items in their categories in order to make decisions about things such as renting or owning a home, owning a car vs. using public transportation, private vs. public schools, and so on by actually going grocery shopping, finding housing, and calling about insurance. The ultimate goal is to access as many resources as possible as economically as possible in order to stay within the annual poverty budget figure for that year $(\$ 18,850$ for a family of four in 2004 in the 48 contiguous states according to the United States Department of Health and Human Services). On the assigned day, students bring to class their notes about how they arrived at their figures and explain their choices to the rest of their classmates.

In the classroom, a sheet of newsprint is posted on the wall for each budget category with all the line items listed for each category. Each group presents their research to the class, fills in the budgeted numbers for each line item in their categories, and subtotals that budget category on the newsprint. On the final sheet of paper, the class excitedly totals all the subtotals to find out how close their grand total comes to the federal poverty line. This entire process is accompanied by much discussion about how various monetary decisions could be 
made and how poverty ultimately limits choices. Over the five years of using this class exercise, one class came in at double the poverty line threshold. The class that came in the closest to the actual figure forgot several items, such as disposable diapers for the two-year-old child.

The exercise concludes with students writing a reaction paper after the classroom part of the exercise is conducted. Students respond to concerns such as: a) personal beliefs about the reasonableness of the government poverty-line calculation in representing the funds on which a family of four is expected to live; b) necessary vs. unnecessary budget items not really thought about prior to this assignment as well as where to cut this budget; $c$ ) how has completing this assignment influenced thoughts about how poverty is defined or how one defines an adequate standard of living; and d) any ideas for policy changes.

Even students who have graduated continue to report that this exercise made a lasting impact on their understanding of poverty and how macropolicy affects families in microways on a daily basis. The reaction papers repeatedly reveal changed self-awareness on both cognitive and affective levels from both students who have and have not been touched by poverty in their lives. Students also begin to understand how they can consciously make choices as social workers that can influence policy change and its implementation.

\section{Unconscious Mannerisms}

Distracting personal habits that can interfere with relationship building comprise the fourth category of Sheafor and Horejsi's (2003) list. Many are unaware of fidgeting, nail biting, hair twisting, excessive nervous laughter, and other distracting mannerisms. Although role-playing exercises in class can be a beginning in addressing this factor, greatly increased awareness of one's unconscious mannerisms is an important side benefit to using audio and/or video taping assignments for learning and practicing interviewing skills. Using a progression of taping assignments improves students' abilities to gain the most selfawareness about both interview skills and personal mannerisms due to both decreasing apprehension about the taping and to increased support and feedback from going through multiple escalating exercises with the same partners.

Progressive Audio/Video Role-Playing Assignment The following audio/video taping teaching strategy includes a progression of three assignments conducted by students with the same partners for each 10 to 15 minute completed interview segment. In addition to instructor evaluation, partners evaluate each other, and students also complete a short paper about what it was like to complete each interview. A simple structured form is provided for students to evaluate partners on five interviewing criteria using a scale of 0 to 3 . Along with discussion of the context of evaluation being a major social work function (such as assessing child abuse risk, community needs, etc.), guidelines are provided regarding constructive feedback. 
While learning interviewing skills in this assignment, students choose a hypothetical case they wish to work with as a "social worker" (crisis, residential treatment, chemical dependency, etc.) but are required to work with a client who is dramatically different from them in at least three ways. Choices go beyond the usual diversity list of gender, race, class, religion, and sexual orientation, to include differences, such as: "If you are single, imagine that the client is married" or "If you have children, pretend that the client has none." In acting out and listening to these chosen differences, stereotypes and misinformation can easily be addressed in class discussion as well as with written instructor feedback.

The first of the three interviews in the assignment involves practicing a firsttime telephone contact. Besides emphasizing how much social work happens by telephone where there is only verbal communication, this beginning assignment also serves to initiate the relationship between the three students in the group (playing rotating roles of interviewer, interviewee, and observer roles) and calms some initial jitters about being taped without being on camera. The second audiotape completes a segment of an initial face-to-face interview. In this progression, students begin to improve their verbal mannerisms (such as repeatedly saying okay) before having to take on nonverbal mannerisms (such as excessive head nodding) in the videotape. Completing two audiotapes together eases the group into the final videotaping of a client interview segment. Although overwhelmed and intimidated by the total assignment initially, students repeatedly report that they are glad to have had the progression of all three taped interviews through which they realize that they have improved their skills.

\section{Additional Benefits of Role Playing and Audio/Visual Taping Assignments}

Difficulties in Verbal Communication The fifth factor in Sheafor and Horejsi's (2003) list, difficulties in verbal communication, is also addressed through audio/video taping assignments. Difficulties in verbal communication include uncorrected vision or hearing problems, inappropriate voice tone or level, or frequent use of slang or poor grammar that contributes to clients' confusion. Audio and video taping assignments address such problems from three perspectives: that of the student (if such difficulties are recognized by the student after hearing or viewing the tapes), that of the other partner students, and that of the instructor who grades the assignment. Structured feedback from such assignments then allows several avenues from which to approach the student whose voice tone is monotone or who continually asks for information to be repeated due to organic hearing problems.

In addition, assignments using role playing and audio/video taping of developing interviewing skills remind students of the importance of first impressions and how others may perceive them. Students see for themselves and get feedback from others regarding what they do well, where they need to improve, and what 
personal idiosyncrasies may detract from the development of a solid helping relationship with a client. Discovery of attitudes, beliefs, or behaviors that are resistant to change in themselves or other students confirm not only the value of increased self-awareness, but also the need for motivation and the ability to bring about internal change. How self-awareness contributes to conscious use of self becomes glaringly apparent to most students through such assignments.

\section{Cautions}

Engaging in activities that increase self-awareness also entails risks, which should be explained for the student just as they would be for clients. Risks for students include others knowing private information about them or their family as in the case of sharing genograms and ecomaps. Discovering aspects of oneself that were previously unknown is usually both exciting and disquieting. Students risk self-understanding that may not be as they wish to be known, particularly in receiving feedback from others. Uncovering new memories or perhaps even revisiting old wounds is not accomplished easily. For some students, exploring their relationships with family and others involves the risk of bringing into the open unhealthy and potentially harmful behaviors and/or beliefs. Developing a level of trust for sharing about one's self with others is necessary.

Boundaries of confidentiality must be acknowledged for classroom assignments, especially those that may include components of sharing with others in the class. At the first class, students enter into a discussion about confidentiality and the importance of keeping information shared by one's self and others private. The instructor cautions students that, in the case of sharing materials or reacting in ways that indicate a problem area that may necessitate further growth and development, the instructor has the responsibility to inform the student of the concern and make an appropriate referral. Students can feel safer in the examination and sharing of self when they understand these boundaries. By the end of this process and initial class, the benefits of becoming an instrument of change with increased self-understanding and a solid ability to consciously use oneself for the betterment of others becomes apparent.

\section{Conclusion}

Sheafor and Horejsi (2003) state: "The skilled worker is purposeful in making use of his or her unique manner and style of relating to others and building positive helping relationships with clients is fundamental to social work practice" (p. 69). Teaching strategies such as those suggested direct students toward understanding the scope of possibilities that minimal self-awareness can affect as well as how increased understanding of oneself can enhance their own potential to effectively engage in the conscious use of self as a social worker. Development of cultural competence as well as conscious use of self can only be 
enhanced through integration with each other. Both authors report that outcome measures such as student evaluations, journals, and seminar discussions continue to demonstrate that these kinds of assignments establish a beginning level of understanding of self-awareness, conscious use of self, and cultural competence in most undergraduate students.

However as budding social workers, students need to be reminded that they are just beginning the ongoing process of refinement of conscious use of self and that it applies at micro-, mezzo-, and macrolevels of intervention. Knowing that NASW (2000) has identified standards for incorporating cultural competence within the practice of the profession stresses the importance of the concept. Along with learning other foundational skills in areas such as communication and interviewing, emphasizing the importance of incorporating cultural competence within the development of one's conscious use of self in undergraduate students is vital to their ability to develop effective helping relationships as future social workers. By utilizing teaching strategies that renew the emphasis of cultural and self-awareness as it is related to the development of conscious use of self and cultural competency, the resulting social workers will be more in tune with themselves as individuals as well as being more prepared for conducting effective helping relationships while harmonizing with a wide variety of client populations and systems.

\section{References}

Cournoyer, B. (2000). The social work skills workbook (3rd ed.). Belmont, CA: Wadsworth.

Hart, M. E. (1992). A person of color: Overcoming barriers to group participation. Moving Forward Online, 2, 1-6.

Ivey, A. E., \& Ivey, M. B. (1999). Intentional interviewing \& counseling: Facilitating client development in a multicultural society (4th ed.). Pacific Grove, CA: Brooks/Cole.

Jacobson, W. B. (2001). Beyond therapy: Bringing social work back to human services reform. Social Work, 46(1), 51-62.

Lee, L. (1983, July/August). The social worker in the political environment of a school system. Social Work, 302-307.

Lieberman, A. A. (1998). The social workout book strength-building exercises for the pre-professional. Thousand Oaks, CA: Pine Forge Press.

Leiby, J. (1997). Social work and social responsibility. In M. Reisch \& E. Gambrill (Eds.), Social work in the 21st century (pp. 359-367). Thousand Oaks, CA: Pine Forge Press.

National Association of Social Workers. (1996). Code of ethics. Washington, DC: NASW Press.

National Association of Social Workers. (2000). Cultural competence in the social work profession. In Social work speaks: NASW policy statements, (pp. 59-62). Washington, DC: NASW Press. 
National Association of Social Workers. (2001). NASW standards for cultural competence in social work practice. Washington, DC: NASW Press.

Neuman, K. M., \& Friedman, B. D. (1997). Process recordings: Fine-tuning an old instrument. Journal of Social Work Education, 33(2), 237-243.

Sheafor, B. W., \& Horejsi, C. R. (2003). Techniques and guidelines for social work practice (6th ed.). Boston, MA: Allyn \& Bacon.

Shulman, L. (1999). The skills of helping individuals, families, groups, and communities (4th ed.). Itasca, IL: F. E. Peacock Publishers, Inc.

Specht, H., \& Courtney, M. E. (1994). Unfaithful angels: How social work has abandoned its mission. New York: The Free Press.

Strom-Gottfried, K. (1998). Social work practice: Cases, activities, and exercises. Thousand Oaks, CA: Pine Forge Press.

United States Department of Health and Human Services. (n.d.). The 2004 HHS Poverty Guidelines. Retrieved June 9, 2004, from

http://aspe.hhs.gov/

poverty/04poverty.shtml

Wegscheider, S. (1981). Another chance. Palo Alto, CA: Science \& Behavior Books. 
Copyright of Journal of Baccalaureate Social Work is the property of Journal of Baccalaureate Social Work. The copyright in an individual article may be maintained by the author in certain cases. Content may not be copied or emailed to multiple sites or posted to a listserv without the copyright holder's express written permission. However, users may print, download, or email articles for individual use. 